\title{
Density Functional Theory Calculations of the Effects of Local Composition and Defect Structure on the Proton Affinity of $\mathrm{H}-\mathrm{ZSM}-5$
}

\author{
Nick O. Gonzales, ${ }^{\dagger}$ Alexis T. Bell, ${ }^{*}, \dagger$ and Arup K. Chakraborty \\ Materials Sciences Division, Lawrence Berkeley National Laboratory, \\ and Department of Chemical Engineering, University of California, Berkeley, California 94720-1462, \\ and Department of Chemistry, University of California, Berkeley, California 94720-1462
}

Received: April 29, 1997; In Final Form: July 26, $1997^{\circledR}$

\begin{abstract}
Density functional theory has been used to determine the effects of local composition and structure on the proton affinity (PA) of $\mathrm{H}-\mathrm{ZSM}-5$. These calculations were performed with clusters ranging in size from 34 to 41 atoms. For isolated $\mathrm{Al}$ sites, the associated PA is $329 \mathrm{kcal} / \mathrm{mol}$. Introduction of a defect in the form of a silanol group immediately adjacent to such a Brønsted acid site reduces the PA to $316 \mathrm{kcal} / \mathrm{mol}$. For an isolated structure containing two $\mathrm{Al}$ atoms in next-nearest-neighbor $\mathrm{T}$ sites, the value of PA lies between 330 and $298 \mathrm{kcal} / \mathrm{mol}$, depending on the location of the two charge-compensating cations, and is not affected by the presence of a silanol group on the $\mathrm{Si}$ atom situated between the two $\mathrm{Al}$ atoms. However, the presence of a trigonally coordinated $\mathrm{Si}$ atom immediately adjacent to the Brønsted acid site reduces the PA dramatically to $281 \mathrm{kcal} / \mathrm{mol}$, but the presence of trigonally coordinated $\mathrm{Al}$ in the vicinity of a Brønsted acid site has no effect on the value of PA. However, the presence of an extraframework Lewis acid center in the form of $\mathrm{Al}=\mathrm{O}^{+}$will lower the PA for a proton associated with one of the $\mathrm{Al}$ atoms in a structure containing two next-nearest-neighbor $\mathrm{Al}$ atoms, to $305 \mathrm{kcal} / \mathrm{mol}$. Defects situated on $\mathrm{Al}$ atoms have PAs lying between 338 and $320 \mathrm{kcal} / \mathrm{mol}$.
\end{abstract}

\section{Introduction}

$\mathrm{H}-\mathrm{ZSM}-5$ is a medium-pore zeolite with many industrial applications, such as the cracking of petroleum to products in the liquid fuel range, the selective production of $p$-xylene from toluene, and the conversion of methanol to olefins or gasoline. ${ }^{1}$ The catalytically active sites in all of these cases are Brønsted acidic, bridging hydroxyl groups associated with framework aluminum atoms. Previous studies have shown that the activity of the Brønsted acid sites depends on both the $\mathrm{Si} / \mathrm{Al}$ ratio and the extent to which the zeolite has been treated in steam, either during the final stages of synthesis or prior to use. For example, studies of hexane and hexene cracking, toluene disproportionation, and the first step in methanol conversion to gasoline show that H-ZSM-5 unaffected by steam exhibits a linear increase in activity with increasing $\mathrm{Al}$ content for $\mathrm{Si} / \mathrm{Al}>18$, suggesting that all of the Brønsted acid sites are isolated from each other and have the same intrinsic activity. ${ }^{2}$ Consistent with this, the ${ }^{1} \mathrm{H}$ NMR chemical shift and the vibrational frequency of the bridging hydroxyl group are found to be independent of the $\mathrm{Si} / \mathrm{Al}$ ratio for $\mathrm{Si} / \mathrm{Al}>10 .^{3}$ Mild steaming of $\mathrm{H}-\mathrm{ZSM}-5$ enhances the specific activity of the Brønsted acid sites for hexane cracking by $45-75$-fold. ${ }^{4}$ The number of enhanced sites created by steaming is a strong function of the $\mathrm{Al}$ content of the zeolite and is dependent upon the number of paired $\mathrm{Al}$ sites in the unsteamed zeolite. ${ }^{4}$ Physical characterization of H-ZSM-5 following mild steaming shows evidence of a loss in the number of Brønsted acid sites due to dehydroxylation, but no indication of dealumination. ${ }^{5}$ The only species observed by ${ }^{1} \mathrm{H}$ NMR, ${ }^{27}$ $\mathrm{Al} \mathrm{NMR}$, and infrared spectroscopy are $\mathrm{Si}-\mathrm{OH}-\mathrm{Al}$ species associated with strong Brønsted acidity, nonacidic terminal $\mathrm{Si}-$ $\mathrm{OH}$ groups, and weakly acidic hydroxylated aluminum species. ${ }^{6}$ No enhancement in the specific activity of Brønsted acid sties is observed for severe steaming (high temperature and water partial pressure), and such pretreatment results in significant

\footnotetext{
Materials Science Division and Department of Chemical Engineering.

$¥$ Department of Chemistry.

${ }^{\otimes}$ Abstract published in Advance ACS Abstracts, October 15, 1997.
}

delaumination of the zeolite framework and the deposition of extraframework alumina species in the pores. ${ }^{4-14}$ Several authors have suggested that both dehydroxylation and dealumination of the zeolite results in the formation of Lewis acid centers via the following processes: ${ }^{5,15-18}$

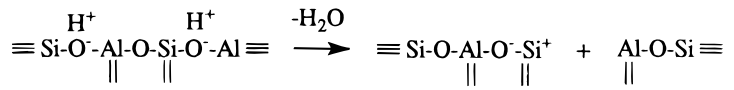

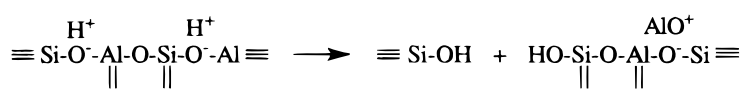

In other studies, it has been proposed that dehydroxylation can occur as well via the reaction of acidic bridging hydroxyl groups with silanol hydroxyl groups present at defects in the lattice. ${ }^{17}$ This process is illustrated by reaction 3. Quantum chemical

$$
\stackrel{\mathrm{H}^{+}}{\mathrm{Si}-\mathrm{O}^{-}-\mathrm{Al}} \equiv+\mathrm{HO}-\mathrm{Si} \equiv \stackrel{-\mathrm{H}_{2} \mathrm{O}}{\longrightarrow} \equiv \mathrm{Si}-\mathrm{O}^{-}-\mathrm{Al} \equiv+{ }^{+} \mathrm{Si} \equiv
$$

calculations indicate that dehydroxylation via reaction 3 is significantly less endothermic than via reaction $1 .{ }^{19}$ The trigonally coordinated $\mathrm{Si}$ atom formed in reactions 2 and 3 is Lewis acidic, and it has been proposed that the proximity of such a site to a Brønsted acid site will increase the acidity of the latter site and thereby increase its catalytic activity. ${ }^{17,20}$ Increased Brønsted acidity has also been attributed to extraframework $\mathrm{Al}=\mathrm{O}^{+}$present as charge-compensating cations in the proximity of Brønsted acid sites. ${ }^{12}$

The effects of local composition and structure on the acidity of ZSM-5 have recently been investigated by means of quantum mechanical calculations. ${ }^{21-27}$ In these studies the strength of the Brønsted acid site is most often characterized by the proton affinity (PA), which is defined as the energy difference between the geometry optimized protonated and deprotonated (anionic) forms of the zeolite. It should be noted, though, that PA provides one measure of acidity, since the effects of differing conjugate base strengths are completely ignored. As discussed 


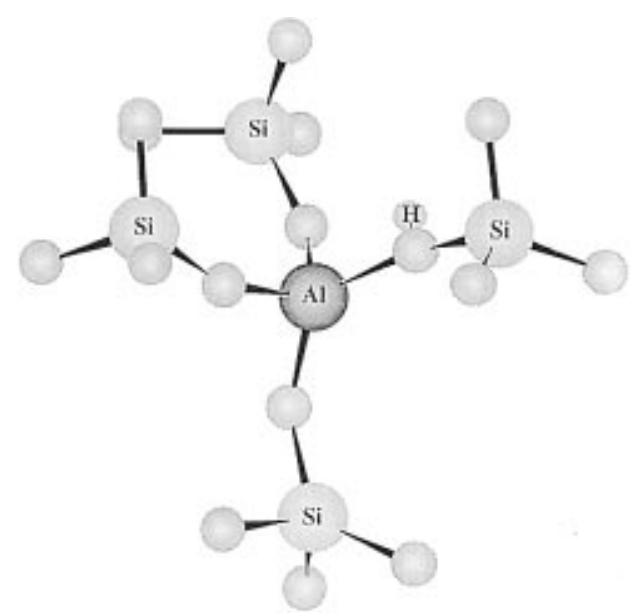

Figure 1. 34-atom acidic zeolite cluster. The proton affinity is 333 $\mathrm{kcal} / \mathrm{mol}$. The bond terminating hydrogen atoms are deleted for clarity.

in more detail below, quantum chemical calculations for isolated Brønsted acid sites have yielded values of PA ranging from 280 to $395 \mathrm{kcal} / \mathrm{mol}$. This broad range encompasses the experimentally observed values of PA, $284-318 \mathrm{kcal} / \mathrm{mol},{ }^{28}$ and reflects, to a large extent, details of the specific computations. These include the size and geometry of the cluster used to represent the Brønsted acid site, the level of theory used, the choice of basis set, and the number of atoms allowed to undergo geometric relaxation. Only one set of calculations has explored the effects of next-nearest-neighbor $\mathrm{Al}$ atoms on the PA of Brønsted acid sites. ${ }^{26}$ This work has shown that introduction of $\mathrm{Al}$ into next-nearest-neighbor $\mathrm{T}$ sites decreases the PA of the Brønsted acid site.

In the present study we investigate the effects of vicinal $\mathrm{Al}$ atoms and defects on the acidity of Brønsted acid sites in $\mathrm{H}-\mathrm{ZSM}-5$, as well as the effects of Lewis acid sites located adjacent to Brønsted acid sites. The influence of local site composition and structure was probed by calculating the PA, as well as the HOMO-LUMO energy difference. The results of these calculations shed considerable light on the origin of the enhanced catalytic activity of $\mathrm{H}-\mathrm{ZSM}-5$ observed upon mild steaming.

\section{Theoretical Approach}

The Brønsted acid site in $\mathrm{H}-\mathrm{ZSM}-5$ is represented by two types of clusters The first is shown in Figure 1 and contains 34 atoms with $\mathrm{Al}$ located at the $\mathrm{T} 12$ site. The $\mathrm{T} 12$ site resides at the intersection of the straight channel and sinusoidal channels and has been identified in semiempirical quantum calculations as the energetically preferred location for $\mathrm{Al} .{ }^{29} \mathrm{Si}, \mathrm{Al}$, and $\mathrm{O}$ atoms are located initially at their crystallographic coordinates. ${ }^{30}$ Hydrogen atoms used to terminate the cluster are located at a distance of $1 \AA$ from the corresponding $\mathrm{O}$ atoms and are oriented along the bond direction to what would otherwise have been the next $\mathrm{Si}$ atom. With the exception of the terminating $\mathrm{OH}$ groups, all of the atoms in the cluster are allowed to relax geometrically during the course of the calculation. For the corresponding anion, the proton is removed from the optimized acid geometry and the anion geometry is then reoptimized. Calculations were also performed for a second cluster containing 40 atoms (shown in Figure 2). This cluster is similar to the 34-atom cluster but extends the zeolite structure along the rim of the 10-membered straight channel. For all cases investigated, the PA is calculated for the proton closest to the center of the cluster. Defects are introduced by allowing $\mathrm{OH}$ groups which were previously constrained to their crystallographic positions to relax freely.

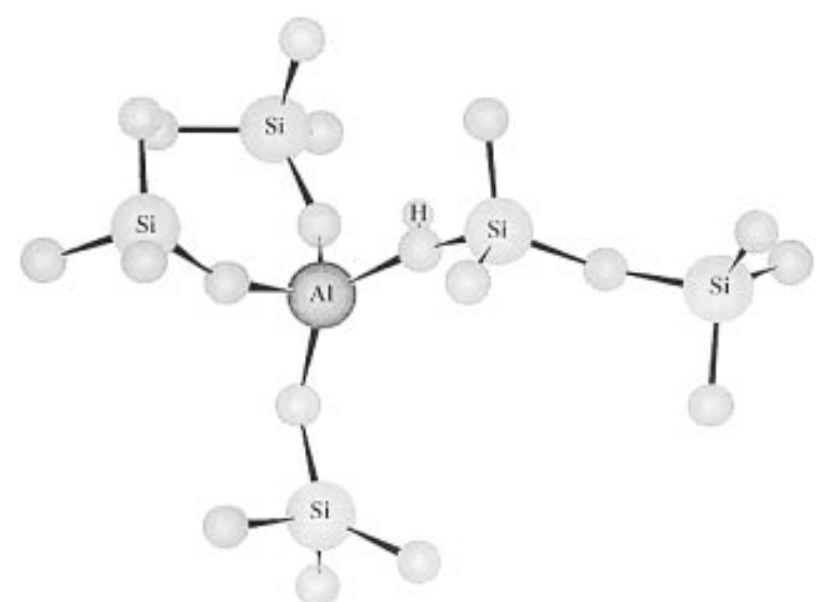

Figure 2. 40-atom extended acidic zeolite cluster. The proton affinity is $329 \mathrm{kcal} / \mathrm{mol}$. The bond terminating hydrogen atoms are deleted for clarity.

Gradient-corrected density functional theory (DFT) implemented within the PSGVB suite of programs ${ }^{31}$ was used to determine cluster geometries and energies. The B3LYP hybrid method $^{32}$ was used to represent the exchange and correlation energies. To minimize the computational time needed for a run, we first carried out Hartree-Fock (HF) geometry optimizations. These calculations provided the initial estimate of the cluster geometry for the more computationally demanding DFT calculations. The geometrical convergence criterion for the smallest acceptable force on the nuclei from the total electron distribution was loosened because distortions of the $\mathrm{Si}-\mathrm{O}-\mathrm{Si}$ and $\mathrm{Si}-\mathrm{O}-\mathrm{Al}$ bond angles have very small energy penalties. With a relaxed convergence criterion, fewer steps are needed to reach the minimum of the potential energy surface and the computational cost is reduced with a minor loss in accuracy.

Basis sets at the 6-31G level ${ }^{33}$ were used for the $\mathrm{O}$ and $\mathrm{H}$ atoms, while the effective core potentials (ECPs) of Hay and Wadt, ${ }^{34}$ with the associated valence basis sets, were used for the $\mathrm{Si}$ and $\mathrm{Al}$ atoms in our cluster. Since Hay ${ }^{35}$ has recently expressed some concern about using the associated valence basis sets of his ECPs for DFT calculations, we compared the PA of two of our clusters by using the approach of Hay and Wadt with that determined by using all-electron basis sets. Using our 34- and 41-atom clusters with no geometry optimization, the approach of Hay and Wadt gave PA's of 287 and $264 \mathrm{kcal} /$ mol, respectively, whereas all-electron calculations using the 6-31G basis sets gave PA's of 286 and $263 \mathrm{kcal} / \mathrm{mol}$, respectively. We also tested the effect of including diffuse basis functions on our estimates of the PA for our clusters with the largest and smallest PAs. It is well-known that inclusion of diffuse functions preferentially lowers the energy of an anion relative to a neutral species because such functions allow the electron distribution more radial flexibility, a property that is more important for an anion than for a neutral structure. Since the computational cost of including diffuse functions is very high due to the $\mathrm{N}^{4}$ scaling of the methods, only a few such calculations were made using such basis functions. These calculations demonstrated that inclusion of diffuse functions lowers PA by $10 \mathrm{kcal} / \mathrm{mol}$ for the structures exhibiting the highest and lowest values of PA. As a consequence it is concluded that neglect of diffuse functions will not affect our conclusions concerning the effects of local composition and structure on the PA. No corrections were made for basis-set superposition error, nor were zero point energy corrections accounted for in calculating energy differences. 


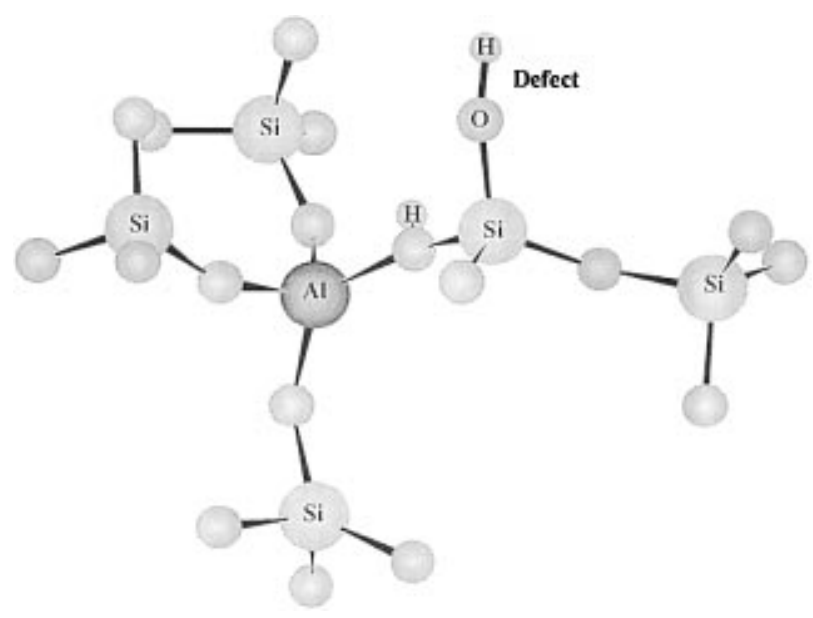

Figure 3. 40-atom extended acidic zeolite cluster with a structural defect on the T12 silicon atom. The proton affinity is $316 \mathrm{kcal} / \mathrm{mol}$. The bond terminating hydrogen atoms are deleted for clarity.

\section{Results and Discussion}

Figure 1 shows the structure of the 34-atom cluster containing a single $\mathrm{Al}$ atom located in the $\mathrm{T} 12$ site. The PA for the Brønsted acid in this case is $333 \mathrm{kcal} / \mathrm{mol}$, and the HOMOLUMO energy difference is $146 \mathrm{kcal} / \mathrm{mol}$. The $\mathrm{H}-\mathrm{O}$ and $\mathrm{H}-\mathrm{Al}$ distances for the Brønsted acid proton are 0.98 and $2.37 \AA$, respectively. The $\mathrm{Al}-\mathrm{O}-\mathrm{Si}$ bond angle is $134^{\circ}$, and the angle between the $\mathrm{Al}-\mathrm{O}-\mathrm{Si}$ plane and the $\mathrm{O}-\mathrm{H}$ bond is $5^{\circ}$. On the basis of the Mulliken population, the charge on the Brønsted acid proton is $0.5|e|$. Our value of $\mathrm{PA}$ is $9 \mathrm{kcal} / \mathrm{mol}$ lower than that we have previously reported for the same cluster on the basis of LDA DFT calculations using the Huzenaga basis sets. ${ }^{27}$ We also observe that our calculated value of the $\mathrm{H}-\mathrm{Al}$ distance is in good agreement with that recently determined from ${ }^{1} \mathrm{H}^{-27} \mathrm{Al}$ SEDOR NMR experiments, $2.43 \AA$ A, ${ }^{36}$ but the angle between $\mathrm{Al}-\mathrm{O}-\mathrm{Si}$ and $\mathrm{O}-\mathrm{H}$ is significantly smaller than the value of $55^{\circ}$ for $\mathrm{H}-\mathrm{ZSM}-5$ estimated from ${ }^{2} \mathrm{H}$ NMR experiments and closer to the value to $12^{\circ}$ estimated for $\mathrm{H}-\mathrm{Y}$ zeolite. ${ }^{37}$

Extension of the cluster along the rim of the straight channel to a total cluster size of 40 atoms, as shown in Figure 2, results in a slight reduction of the PA to $329 \mathrm{kcal} / \mathrm{mol}$, and placement of the proton on one of the other three $\mathrm{O}$ atoms connected to the central $\mathrm{Al}$ atom raises the PA only slightly to a value of $330 \mathrm{kcal} / \mathrm{mol}$. However, when the proton is again located toward the center of the cluster and a defect is introduced on the adjacent Si atom (Figure 3), the PA decreases from 329 to $316 \mathrm{kcal} / \mathrm{mol}$ and there is a corresponding decrease in the HOMO-LUMO gap. The decrease in the PA is attributable to the difference in the greater effects of the defect on the absolute energy of the deprotonated (anionic) versus the protonated form of the cluster. Introduction of the defect lowers the absolute energy of the protonated structure by $13 \mathrm{kcal} / \mathrm{mol}$ but lowers the absolute energy of the deprotonated structure by $26 \mathrm{kcal} / \mathrm{mol}$. We note that if the Brønsted acid site is moved from the immediate vicinity of the defect, it has no significant effect on the PA.
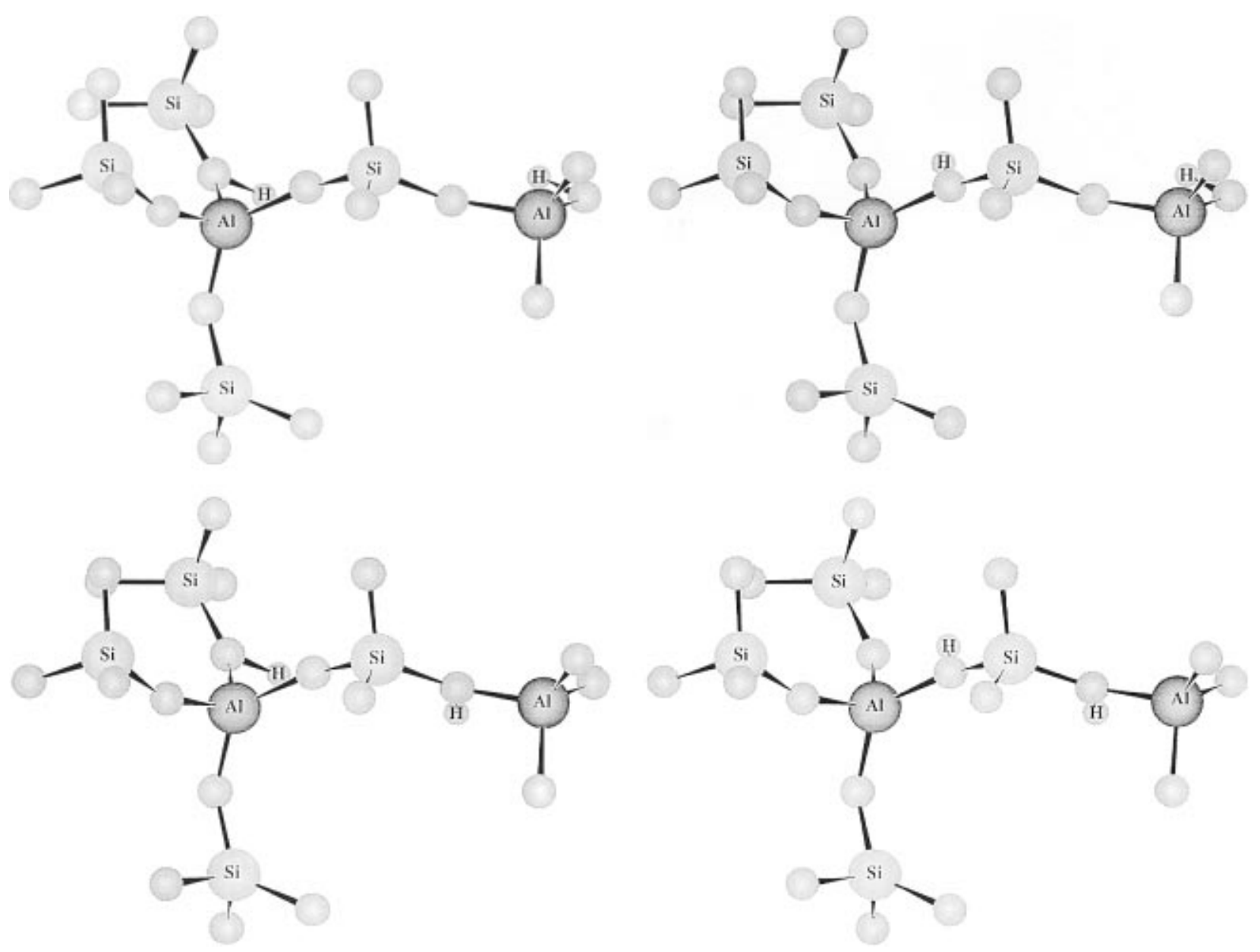

Figure 4. 41-atom extended acidic zeolite cluster with a second aluminum atom at the next-nearest-neighbor position. The terminating hydrogen atoms are deleted for clarity. The two charge-compensating protons are separated (a, top, left) by the maximum distance of $5.7 \AA$ (PA $=328$ $\mathrm{kcal} / \mathrm{mol})$, (b, top, right) by $3.5 \AA(\mathrm{PA}=330 \mathrm{kcal} / \mathrm{mol})$, (c, bottom, left) by $4.4 \AA(\mathrm{PA}=318 \mathrm{kcal} / \mathrm{mol})$, and $(\mathrm{d}$, bottom, right) by $2.5 \AA(\mathrm{PA}=$ $298 \mathrm{kcal} / \mathrm{mol}$ ). 


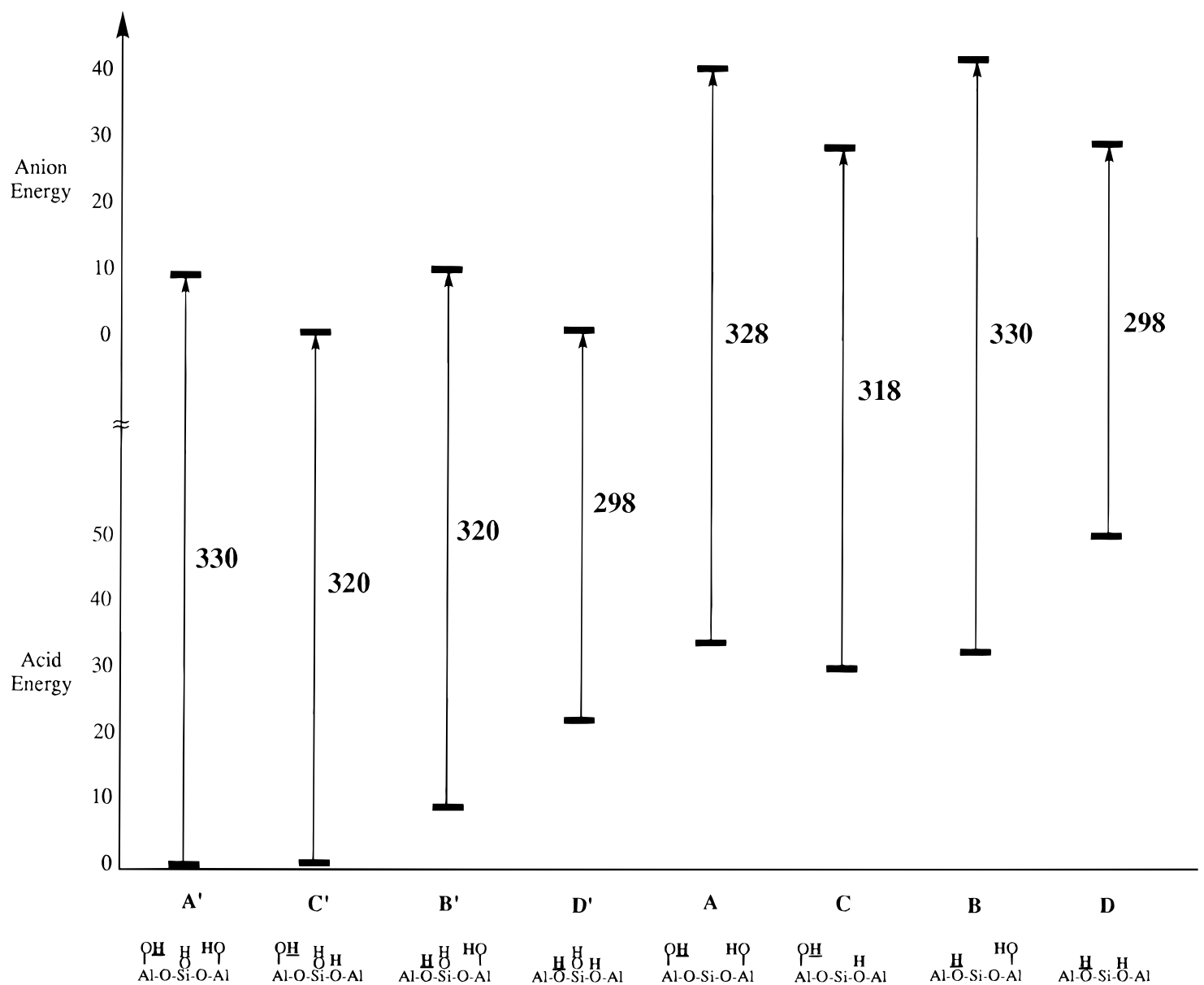

Figure 5. Energies of the eight different 41 -atom clusters and their anions. The energy of acid structure $A^{\prime}$ has been set to zero. A structural defect is depicted by an $\mathrm{OH}$ group on the T12 silicon atom. The first four clusters $\left(\mathrm{A}^{\prime}-\mathrm{D}^{\prime}\right)$ contain structural defects, and the second four structures $(A-D)$ represent the defect-free structures presented in Figure $4(a-d)$. The proton affinities have been calculated for the hydrogen atoms that are underlined in each structure. The energy units in all cases are kilocalories per mole.

If a second aluminum atom is placed at a next-nearestneighbor position relative to the original site, there are a number of alternative positions for placement of the two charge compensating protons. Two sites for each proton were considered, for a total of four structures with the same composition as that shown in Figure 4 . When the proton is placed on the side of the cluster and the second charge compensating proton is placed on the terminating $\mathrm{OH}$ group at the far end of the cluster (Figure $4 \mathrm{a}$ ), the PA is $328 \mathrm{kcal} / \mathrm{mol}$. Placing the first proton at the center of the cluster and the second proton at the terminating $-\mathrm{OH}$ group (Figure $4 \mathrm{~b}$ ) raises the PA by only 2 $\mathrm{kcal} / \mathrm{mol}$ to $330 \mathrm{kcal} / \mathrm{mol}$. The values of PA for the structures shown in Figures $4 \mathrm{a}, \mathrm{b}$ are essentially the same as that determined for the identical cluster containing only a single $\mathrm{Al}$ atom; however, introduction of the second $\mathrm{Al}$ atom does cause a decrease in the HOMO-LUMO gap. When the acidic proton is placed on the side of the cluster as shown in Figure $4 \mathrm{c}$ and the second proton on the far side of the $\mathrm{Si}(\mathrm{OH})_{2}$ bridge, the PA drops to $318 \mathrm{kcal} / \mathrm{mol}$, and there is a corresponding decrease in the HOMO-LUMO gap. As discussed below, the difference in the values of PA for the structures appearing in Figure 4b,c is attributable to the lower absolute energy of the anionic form of the structure in Figure $4 \mathrm{c}$ relative to that for the structure in Figure $4 \mathrm{~b}$, since the absolute energies of the protonated forms of the two structures are essentially identical. It should be noted, though, that the PA for the structure shown in Figure 4b may be subject to some error since the second charge-compensating proton is located at the edge of the cluster. When the two protons straddle an $\mathrm{Si}(\mathrm{OH})_{2}$ bridge as shown in Figure 4d, the
PA decreases to $298 \mathrm{kcal} / \mathrm{mol}$ and the HOMO-LUMO gap undergoes a further decrease. The trend in PA reported here is similar to that presented by Kramer Van Santen ${ }^{26}$ on the basis of calculations performed with a four $\mathrm{T}$ atom ringed cluster containing two $\mathrm{Al}$ atoms. In that case the PA decreases from $337 \mathrm{kcal} / \mathrm{mol}$ when the two protons are as far apart as possible to $313 \mathrm{kcal} / \mathrm{mol}$ when they are as close as possible.

Figure 5 shows the effect of introducing a defect on the T12 $\mathrm{Si}$ atom on the absolute energies of the protonated and deprotonated 41-atom cluster containing two Al atoms and the corresponding effects on the PA. The presence of a defect lowers the absolute energy of both the protonated and deprotonated structures by between 23 and $35 \mathrm{kcal} / \mathrm{mol}$. For structures A, C, and D the defect has virtually no effect on the $\mathrm{PA}$, and for structure B the reduction in the PA is only $10 \mathrm{kcal} /$ mol. It is notable that in the case of structure B the PA in the absence of the defect is identical with that determined for a 40 -atom cluster containing one $\mathrm{Al}$ atom, and the decrease in the PA upon introducing the defect is nearly identical.

Significant changes in the PA and the HOMO-LUMO gap are observed when the defect is removed by combining the silanol $\mathrm{OH}$ group with one of the Brønsted acid protons. In this case, the $\mathrm{Si}$ atom associated with the defect becomes trigonally bonded and acts as a Lewis acid. The resulting structures are shown in Figure 6. The endothermicity associated with the removal of water is $83 \mathrm{kcal} / \mathrm{mol}$ to produce the structure shown in Figure $6 \mathrm{a}$ and $91 \mathrm{kcal} / \mathrm{mol}$ for the structure shown in Figure $6 \mathrm{~b}$. Assuming that the entropy of the zeolite structures before and after removal of the defect are essentially the same, 


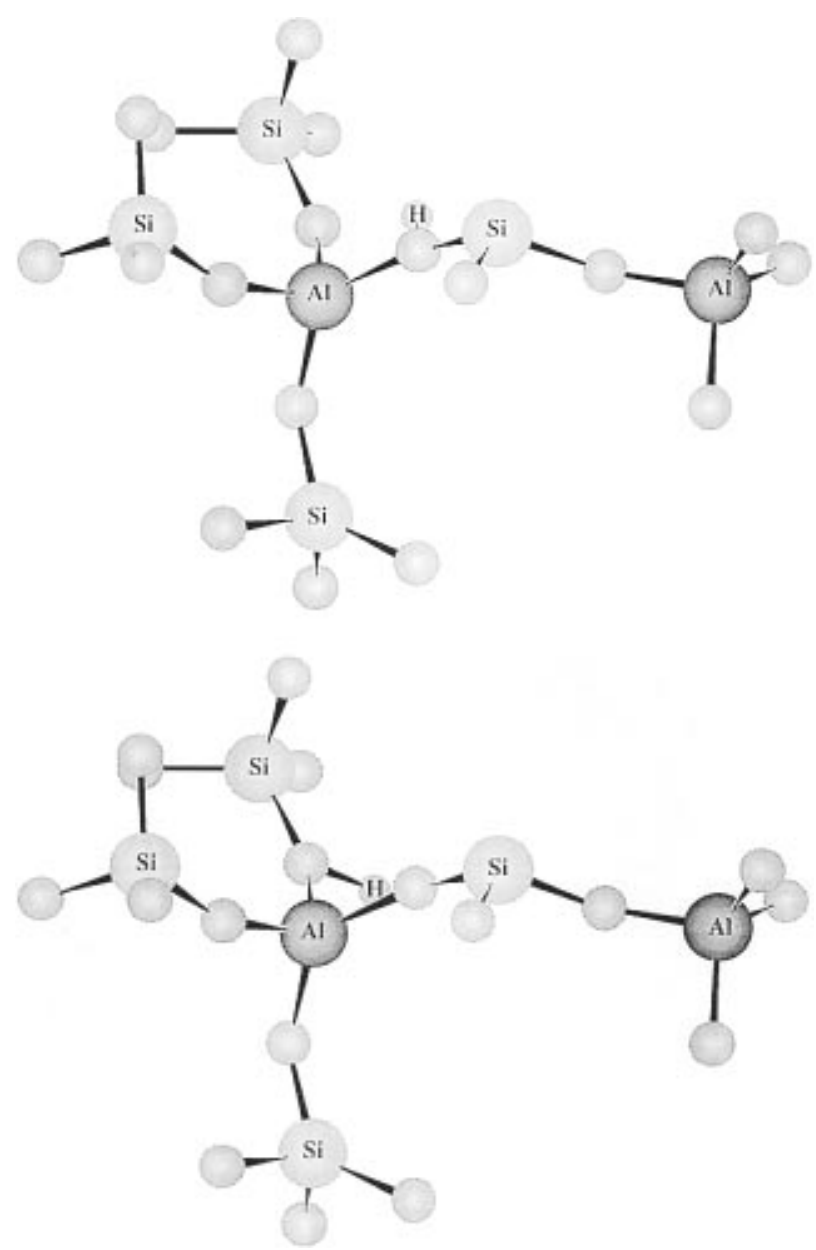

Figure 6. Dehydration of the 41-atom cluster to produce a 38 -atom cluster with a Lewis acid site at the T12 silicon atom. For structure a (top) the proton affinity of a proton adjacent to the Lewis site is 281 $\mathrm{kcal} / \mathrm{mol}$. For structure $\mathrm{b}$ (bottom) the proton affinity of a proton three bonds away from the Lewis acid site is $311 \mathrm{kcal} / \mathrm{mol}$. The bond terminating hydrogen atoms are deleted for clarity.

the entropy for the dehydration process is estimated to be 53.4 $\mathrm{cal} /(\mathrm{mol} \mathrm{K})$. Since the entropy change is positive, this means that the Gibbs free energy of dehydration will become increasingly favorable with increasing temperature.

Figure 6a shows that if the remaining proton is located on an $\mathrm{O}$ atom bonded to the Lewis acid $\mathrm{Si}$, the PA decreases to $281 \mathrm{kcal} / \mathrm{mol}$ and the HOMO-LUMO gap decreases to $48 \mathrm{kcal} /$ mol. These changes indicate that the presence of the Lewis acid center causes the proton to become a stronger but softer acid. Calculations performed for a 58-atom cluster in which the terminating $\mathrm{H}$ atom on the Lewis acid $\mathrm{Si}$ is replaced by an $\mathrm{Si}(\mathrm{OH})_{3}$ group give the same values of the PA and HOMOLUMO gap. When the Brønsted acid proton is moved further away from the Lewis acid site, the PA increases to $311 \mathrm{kcal} /$ mol and the HOMO-LUMO gap increases to $58 \mathrm{kcal} / \mathrm{mol}$. These results clearly demonstrate that the presence of a Lewis acid site on Si will strongly affect the acidity of Brønsted acid sites, as has been suggested by the experimental literature.

The influence on the PA of a Lewis acid center in the form of trigonally coordinated framework $\mathrm{Al}$ and extraframework $\mathrm{Al}=\mathrm{O}^{+}$was investigated. When the Lewis acid center is trigonally coordinated Al, as shown in Figure 7a, the value of PA is $328 \mathrm{kcal} / \mathrm{mol}$. This is virtually the same value as that for a proton associated with an isolated Brønsted acid site (see Figure 2), suggesting that through-cluster communication of electronic structure differences is short range and is a noticeable effect only when the perturbation occurs less than three bonds

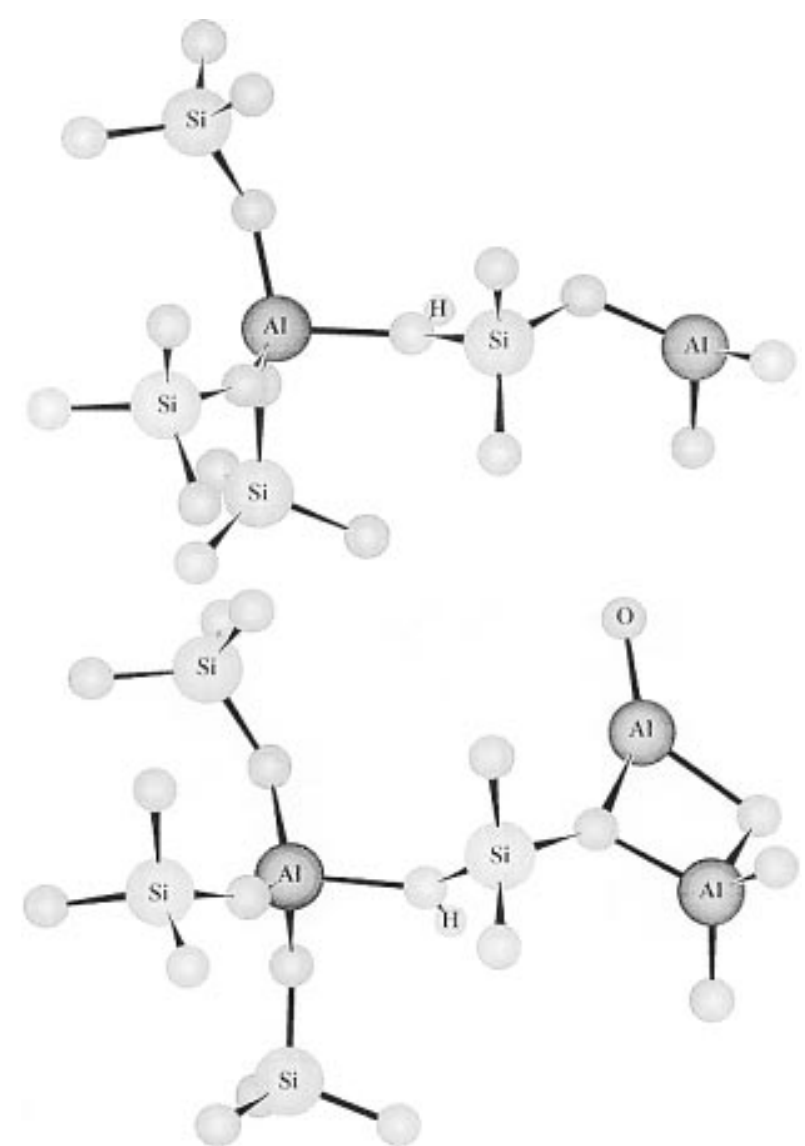

Figure 7. Effects of a distant Lewis acid site on the proton affinity: (a, top) the 39-atom extended cluster with a defect at the second aluminum site $(\mathrm{PA}=328 \mathrm{kcal} / \mathrm{mol})$; (b, bottom) the 42 -extended cluster with a $\mathrm{AlO}^{+}$molecule as the charge-compensating cation for the second zeolitic aluminum $\mathrm{T}$ site $(\mathrm{PA}=305 \mathrm{kcal} / \mathrm{mol})$. The bond terminating hydrogen atoms are deleted for clarity.

from the Brønsted acid center. The PA of the extended cluster with $\mathrm{Al}=\mathrm{O}^{+}$as the charge-compensating cation for the second $\mathrm{Al}$ atom is $305 \mathrm{kcal} / \mathrm{mol}$ and lies between those determined for structures containing two Al atoms (see Figure 4), PA = 298$330 \mathrm{kcal} / \mathrm{mol}$.

We also investigated the effects of defects on the $\mathrm{Al}$ atom located at the T12 site. Figure 8 shows our cluster with one or two defects located on the central $\mathrm{Al}$ atom. The cluster model with one defect consisted of three $-\mathrm{O}-\mathrm{Si}(\mathrm{OH})_{3}$ groups and an $-\mathrm{OH}$ group coordinated to the aluminum center with a chargecompensating proton placed in either of two positions. In Figure $8 \mathrm{a}$ the proton resides on an oxygen of the $-\mathrm{O}-\mathrm{Si}(\mathrm{OH})_{3}$ cluster, whereas in Figure $8 \mathrm{~b}$ the proton resides on the $-\mathrm{OH}$ group which effectively becomes a coordinatively bound $\mathrm{H}_{2} \mathrm{O}$. The PA of the bridging hydroxyl is $327 \mathrm{kcal} / \mathrm{mol}$, and the PA of the coordinatively bound $\mathrm{H}_{2} \mathrm{O}$ is $320 \mathrm{kcal} / \mathrm{mol}$. The $\mathrm{H}_{2} \mathrm{O}$ molecule is bound to the cluster presented in Figure $8 \mathrm{~b}$ by $48 \mathrm{kcal} / \mathrm{mol}$. For the case of two defects on the central T12 Al site, the cluster consists of two $-\mathrm{O}-\mathrm{Si}(\mathrm{OH})_{3}$ groups and two $-\mathrm{OH}$ groups. The charge compensating proton can again reside on the larger siliceous group or as an $\mathrm{H}_{2} \mathrm{O}$ coordinatively bound by $32 \mathrm{kcal} /$ mol. For the case of the proton within the water (Figure 8c) the PA is $331 \mathrm{kcal} / \mathrm{mol}$, and for the proton residing on the bridging hydroxyl group (Figure $8 \mathrm{~d}$ ) the PA is $338 \mathrm{kcal} / \mathrm{mol}$. These results demonstrate that a single defect situated on $\mathrm{Al}$ has relatively little effect on the PA of the Brønsted acid proton and that introduction of a second defect raises the PA only slightly. However, in either case, the more stable structure is one in which the Brønsted acid proton moves to the defect, forming coordinatively bonded $\mathrm{H}_{2} \mathrm{O}$. It is evident from Figure 


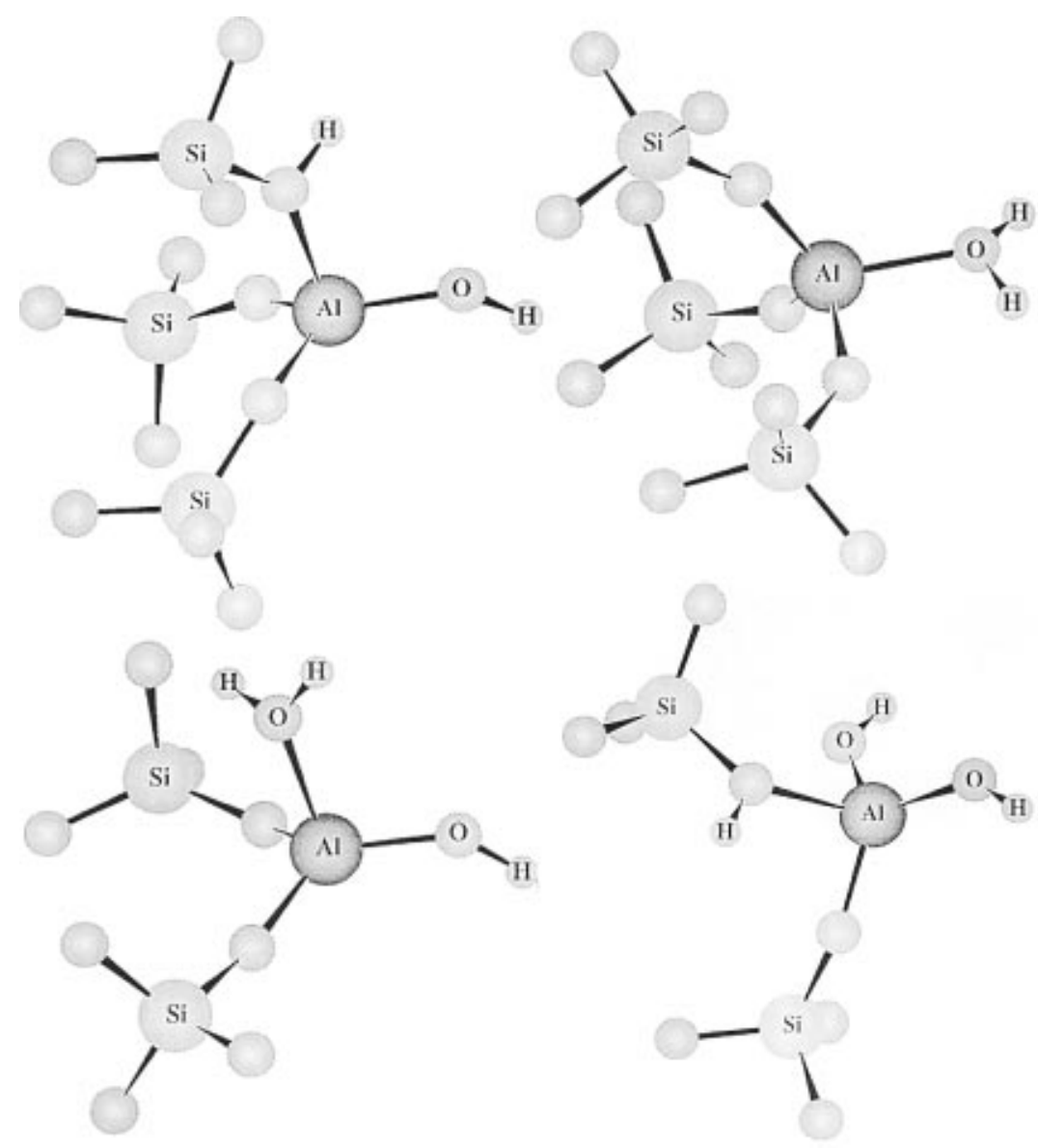

Figure 8. Effects of defects on the central T12 aluminum site: (a, top, left) 28-atom cluster with an OH group mimicking a structural defect (PA $=327 \mathrm{kcal} / \mathrm{mol}$ ); (b, top, right) the same cluster but with the acidic proton residing on the defect (i.e., a coordinatively bound $\mathrm{H}_{2} \mathrm{O} ; \mathrm{PA}=320$ $\mathrm{kcal} / \mathrm{mol}$ ); (c, bottom, left) the 22-atom cluster with one $\mathrm{OH}$ group mimicking a structural defect and a coordinatively bound $\mathrm{H}_{2} \mathrm{O}$ (the proton affinity of the water molecule is $331 \mathrm{kcal} / \mathrm{mol}$ ); (d, bototm, right) the same cluster but with the charge-compensating proton on the zeolite cluster $(\mathrm{PA}=338 \mathrm{kcal} / \mathrm{mol})$. The bond terminating hydrogen atoms are deleted for clarity.

8b,d that such structures have PA's comparable to those determined for the zeolite possessing a defect on a $\mathrm{Si}$ atom adjacent to the Brønsted acid site and the defect-free zeolite, respectively.

It is useful to consider the implications of the present results for catalysis. It is well-known that, as-prepared, ZSM-5 contains defects in roughly equivalent or greater number than the number of Brønsted acid sites. ${ }^{38,39}$ Our results show that defects located on $\mathrm{Si}$ can lower the PA by about $12 \mathrm{kcal} / \mathrm{mol}$, but only if the defect is immediately adjacent to the Brønsted acid site. A defect associated with $\mathrm{Al}$ can have a similar effect on the PA. Since ZSM-5 can only be prepared with $\mathrm{Si} / \mathrm{Al}$ ratios of greater than 10 , the proportion of vicinal $\mathrm{Al}$ atoms (i.e., isolated nextnearest-neighbor ( $\mathrm{NNN}$ ) pairs of $\mathrm{Al}$ atoms) is small. Assuming the distribution of $\mathrm{Al}$ atoms to be completely random, the maximum concentration of $\mathrm{Al} \mathrm{NNN}$ pairs is estimated to be $1.5 \%$ for $\mathrm{Si} / \mathrm{Al}=12 .{ }^{5}$ The presence of such pairs in the defectfree zeolite can cause a decrease in the PA relative to that for isolated Al sites, particularly if the second proton is situated such that both protons are associated with a common $\mathrm{Si}$ atom (see Figure 4d). As noted in the Introduction, dehydroxylation of the zeolite via reaction 3 leads to the formation of a trigonally coordinated $\mathrm{Si}$ atom, which acts as a Lewis acid site. Protons proximate to the Lewis acid center exhibit a reduction in the PA of $50 \mathrm{kcal} / \mathrm{mol}$ and a substantial decrease in their hardness. Since mild steaming can give rise to such Brønsted acid-Lewis acid sites, ${ }^{18,21}$ it is quite conceivable that these sites contribute to the very large rise in catalytic activity observed experimentally after mild steaming. ${ }^{4}$ Lewis acid centers in the form of
$\mathrm{Al}=\mathrm{O}^{+}$can also lower the PA significantly; however, in this case three $\mathrm{Al}$ atoms must be located in immediate proximity to the Brønsted acid site, a condition that is not very probable for $\mathrm{H}-\mathrm{ZSM}-5$ with a Si/Al ratio significantly greater than 10 .

\section{Conclusions}

The proton affinity of $\mathrm{H}-\mathrm{ZSM}-5$ is found to depend on the local composition and structure of the zeolite in the vicinity of the Brønsted acid site. For isolated $\mathrm{Al}$ sites, the associated PA is $329 \mathrm{kcal} / \mathrm{mol}$ on the basis of gradient-corrected density functional calculations carried out with a 40-atom cluster (see Figure 2). Introduction of a defect in the form of a silanol group immediately adjacent to the Brønsted acid site reduces the PA to $316 \mathrm{kcal} / \mathrm{mol}$ (Figure 3). For an isolated structure containing two $\mathrm{Al}$ atoms in next-nearest-neighbor T sites, the value of PA lies between 330 and $298 \mathrm{kcal} / \mathrm{mol}$, depending on the location of the two charge-compensating cations (Figure 4). Defects have very little influence on the PA for such structures (see Figure 5). However, the presence of a trigonally coordinated $\mathrm{Si}$ atom immediately adjacent to the Brønsted acid site reduces the PA dramatically to $281 \mathrm{kcal} / \mathrm{mol}$ (see Figure 6), but the presence of trigonally coordinated $\mathrm{Al}$ in the vicinity of a Brønsted acid site has no effect on the value of PA (see Figure 7) because it cannot be located as close to the Brønsted acid site as the trigonally coordinated $\mathrm{Si}$ atom. The presence of a Lewis acid center in the form of $\mathrm{Al}=\mathrm{O}^{+}$will lower the $\mathrm{PA}$ for a proton associated with one of the $\mathrm{Al}$ atoms in a structure containing two next-nearest-neighbor $\mathrm{Al}$ atoms, to $305 \mathrm{kcal} /$ 
mol (see Figure 7). The occurrence of defects situated on $\mathrm{Al}$ atoms results in the determination of values of PA lying between 338 and $320 \mathrm{kcal} / \mathrm{mol}$ (Figure 8 ). The present results suggest that the increase in catalytic activity of $\mathrm{H}-\mathrm{ZSM}-5$ observed after light steaming of $\mathrm{H}-\mathrm{ZSM}-5$ may be due to the creation of $\mathrm{Si}^{+}$Lewis acid sites immediately adjacent to Brønsted acid sites, since such a perturbation should produce a small number of highly acidic sites.

Acknowledgment. This work was supported by a grant from the Office of Industrial Technology of the U. S. Department of Energy under Contract DE-AC03-76SF00098. Computing resources were provided by the National Energy Research Supercomputing Center and the San Diego Supercomputing Center.

\section{References and Notes}

(1) Chen, N. Y.; Degnan, T. F., Jr.; Smith, C. M. Molecular Transport and Reaction in Zeolites; VCH: New York, 1994.

(2) Haag, W. O. in Proceedings of the Sixth International Zeolite Conference; Olsen, D., Bisio, A., Eds.; Butterworth: Guildford, U.K., 1984; p 466. 62 .

(3) Freude, D.; Hunger, M.; Pfeifer, H. Chem. Phys. Lett. 1986, 128,

(4) Lago, R. M.; Haag, W. O.; Mikovsky, R. J.; Olsen, D. H.; Hellring, S. D.; Schmitt, K. D.; Kerr, G. T. In Studies in Surface Science and Catalysis; Murakami, Y., Iijima, A., Ward, J. W., Eds.; Elsevier: New York, 1986; Vol. 28, p 677.

(5) Sonnemans, M. H. W.; den Heijer, C.; Crocker, M. J. Phys. Chem. 1993, 97,440 .

(6) Maijanen, A.; Derouane, E. G.; Nagy, J. B. Appl. Surf. Sci. 1994, $75,204$.

(7) Jacobs, P. A.; Tielen, M.; Nagy, J. B.; Debras, G.; Derouane, E. G.; Gabelica, Z. in Proceedings of the Sixth International Zeolite Conference; Olsen, D., Bisio, A., Eds.; Butterworth: Guildford, U.K., 1984; p 783.

(8) Klinowski, J.; Thomas, J. M.; Fyfe, C. A.; Gobbi, G. C. Nature 1982, 296, 533.

(9) Freude, D.; Brunner, E.; Pfeifer, H.; Prager, D.; Jerschkewitz, H.G.; Lohse, U.; Oehlmann, G. Chem. Phys. Lett. 1987, 139, 325.

(10) Fyfe, C. A.; Gobbi, G. C.; Kennedy, G. J. J. Phys. Chem. 1984, $88,3248$.

(11) Bosacek, V.; Freude, D.; Frohlich, T.; Pfeifer, H.; Schniedel, H. J. Colloid Interface Sci. 1982, 85, 502.

(12) Brunner, E.; Ernst, H.; Freude, D.; Frohlich, T.; Hunger, M.; Pfeifer, H. J. Catal. 1991, 127, 34 .

(13) Samoson, A.; Lippmaa, E.; Engelhardt, G.; Lohse, U.; Jerschkewitz, H.-G. Chem. Phys. Lett. 1987, 134, 589.
(14) Campbell, S. M.; Bibby, D. M.; Coddington, J. M.; Howe, R. F.; Meinhold, R. H. J Catal. 1996, 161, 338.

(15) Uytterhoeven, L. B.; Cristner, L. G.; Hall, W. K. J. Phys. Chem. 1965, 69, 2117.

(16) Kuhl, G. H. J. Phys. Chem. Solids 1977, 38, 1259.

(17) Kazansky, V. B. Catal. Today 1988, 3, 367.

(18) Lohse, U.; Porlitz, B.; Patzelova, V. J. Phys. Chem. 1989, 93, 3677.

(19) Senchenya, I. N.; Chuvilikin, N. D.; Kazansky, V. B. Kinet. Katal. 1986, $27,87$.

(20) Rakiewicz, E. F.; Mueller, K. T.; Javie, T. P.; Sutovich, K. J.; Roberie, T. G.; Peters, A. W. Microporous Mater. 1996, 7, 81. 7725 .

(22) Brand, H. V.; Curtiss, L. A.; Iton, L. E. J. Phys. Chem. 1992, 97, 12773

(23) Alvarado-Swaisgood, A. E.; Barr, M. K.; Hay, P. J.; Redondo, A. J. Phys. Chem. 1991, 95, 10031.

(24) Nicholas, J. B. In Studies in Surface Science and Catalysis; Hightower, J. W., Delgass, W. N., Iglesia, E., Bell, A. T., Eds.; Elsevier: New York, 1996; Vol. 101, p 1263.

(25) Nicholas, J. B.; Winans, R. E.; Harrison, R. J.; Iton, L. E.; Curtiss, L. A.; Hopfinger, A. J. J. Phys. Chem. 1992, 96, 10247.

(26) Kramer, G. J.; van Santen R. A. J. Am. Chem. Soc. 1993, 115, 2887.

(27) Kyrlidis, A.; Cook, S. J.; Chakraborty, A. K.; Bell, A. T.; Theodorou, D. N. J. Phys. Chem. 1995, 99, 1505.

(28) Datka, J.; Boczar, M.; Rymarowicz, P. J. Catal. 1988, 114, 368.

(29) Lonsinger, S. R.; Chakraborty, A. K.; Theodorou, D. N.; Bell, A.

T. Catal. Lett. 1991, 11, 209.

(30) Olson, D. H.; Kokotailo, G. T.; Lawton, S. 1.; Meier, W. M. J. Phys. Chem. 1981, 85, 2238.

(31) Ringnalda, M. N.; Langlois, J.-M.; Murphy, R. B.; Greeley, B. H.; Cortis, C.; Russo, T. V.; Marten, B.; Donnelly, R. E., Jr.; Pollard, W. T.; Cao, Y.; Muller, R. P.; Mainz, D. T.; Wright, J. R.; Miller, G. H.; Goddard, W. A., III; Friesner, R. A. $P S-G V B$, v2.3; Schrodinger: Portland, OR, 1996.

(32) (a) Becke, A. D. J. Chem. Phys. 1993, 98, 5648. (b) Lee, C.; Yang, W.; Parr, R. G. Phys. Rev. B 1988, 37, 785.

(33) (a) Hehre, W. J.; Ditchfield, R.; Pople, J. A. J. Chem. Phys. 1972, 56, 2257. (b) Dill, J. D.; Pople, J. A. J. Chem. Phys. 1975, 62, 2921. (c) Binkley, J. S.; Pople, J. A. J. Chem. Phys. 1977, 66, 879.

(34) Hay, P. J.; Wadt, W. R. J. Chem. Phys. 1985, 82, 284.

(35) Russo, T. V.; Martin, R. L.; Hay, P. J. J. Phys. Chem. 1995, 99 , 17085 .

(36) Kenaston, N. P.; Bell, A. T.; Reimer, J. H. J. Phys. Chem. 1994, $98,894$.

(37) Kobe, J. M.; Gluszak, T. J.; Dumesic, J. A.; Root, T. W. J. Phys. Chem. 1995, 99, 5485.

(38) Koller, H.; Lobo, R. F.; Burkett, S. L.; Davis, M. E. J. Phys. Chem. 1995, 99, 12588.

(39) Hunger, M.; Karger, J.; Pfeifer, H.; Caro, J.; Zibrowius, B.; Bulow, M.; Mostowicz, R. J. Chem. Soc., Faraday Trans. 1 1987, 83, 3459. 